Gut and Liver, Vol. 9, No. 4, July 2015, pp. 464-469

\title{
Lipase Supplementation before a High-Fat Meal Reduces Perceptions of Fullness in Healthy Subjects
}

\author{
Max E. Levine*, Sara Yanchis Koch ${ }^{\dagger}$, and Kenneth L. Koch ${ }^{\dagger}$ \\ ${ }^{*}$ Department of Psychology, Siena College, Loudonville, NY, and ${ }^{\dagger}$ Section of Gastroenterology, Department of Internal Medicine, Wake Forest \\ University School of Medicine, Winston-Salem, NC, USA
}

See editorial on page 433.

Background/Aims: Postprandial symptoms of fullness and abdominal discomfort are common after fatty meals. Gastric lipases hydrolyze $10 \%$ to $20 \%$ of dietary triglycerides during the stomach trituration period of digestion. The aim of this study was to evaluate the effects of acid-resistant lipase on upper gastrointestinal symptoms, including fullness and bloating, as well as on gastric myoelectrical activity after healthy subjects ingested a high-fat, liquid meal. Methods: This study utilized a double-blind, placebo-controlled, crossover design with 16 healthy volunteers who ingested either a capsule containing $280 \mathrm{mg}$ of acid-resistant lipase or a placebo immediately before a fatty meal (355 calories, 55\% fat). Participants rated their stomach fullness, bloating, and nausea before and at timed intervals for 60 minutes after the meal. Electrogastrograms were obtained to assess the gastric myoelectrical activity. Results: Stomach fullness, bloating, and nausea increased significantly 10 minutes after ingestion of the fatty meal $(p<0.01)$, whereas normal gastric myoelectrical activity decreased and tachygastria increased $(p<0.05)$. With lipase, reports of stomach fullness were significantly lower compared with placebo $(p<0.05)$, but no effect on gastric myoelectrical activity or other upper gastrointestinal symptoms was observed. Conclusions: The high-fat meal induced transient fullness, bloating, nausea, and tachygastria in healthy individuals, consistent with postprandial distress syndrome. Acid-resistant lipase supplementation significantly decreased stomach fullness. (Gut Liver 2015;9:464-469)

Key Words: Lipase supplementation; Gastric myoelectrical activity; Electrogastrography; Dyspepsia symptoms; Fullness; Acid-resistant lipase

\section{INTRODUCTION}

Dyspepsia symptoms of abdominal discomfort, fullness, early satiety, and nausea occur after ingestion of meals in 20\% to $30 \%$ of the population. ${ }^{1,2}$ Complaints of dyspepsia symptoms are common in general medical practice and account for $5 \%$ of all office visits. ${ }^{1}$ If no structural cause of these symptoms (e.g., peptic ulcer disease) can be identified, dyspepsia is labeled postprandial distress syndrome (PDS) or functional epigastric pain syndrome by Rome III definitions. ${ }^{3}$ PDS is the more common type of functional dyspepsia and does not respond to proton pump inhibitor therapies. Meals with high-fat content delay gastric emptying and prolong the sensation of stomach fullness, ${ }^{4}$ and to some extent may induce symptoms of PDS. Pancreatic enzyme supplements containing pancrelipase have been demonstrated to significantly reduce early postprandial symptoms such as bloating in healthy subjects compared with placebo. $^{5}$

The digestion of ingested fat begins in the stomach. Gastric lipases are key enzymes for digesting triglycerides (TG) within the stomach. ${ }^{6,7}$ Gastric lipase secreted by chief cells located in the gastric fundus consitute 5\% to $10 \%$ of the total lipase available for fat digestion., ${ }^{8,9}$ Gastric lipases hydrolyze $10 \%$ to $20 \%$ of the TG in the meal into fatty acids, di- and monoglycerides. ${ }^{10-13}$ The free fatty acids contribute to the stimulation of pancreatic lipase and colipase release from the pancreas. ${ }^{14-16}$ Efficient digestion of fat in the stomach also requires normal gastric neuromuscular activity for mixing and emptying stomach contents.

The aim of this study was to determine the effects of ingesting an acid-resistant lipase capsule or placebo with a high-fat

Correspondence to: Max E. Levine

Department of Psychology, Siena College, 515 Loudon Road, Loudonville, NY 12211, USA

Tel: +1-518-782-6872, Fax: +1-518-783-2986, E-mail: mlevine@siena.edu

Received on January 7, 2014. Revised on March 12, 2014. Accepted on April 8, 2014. Published online October 7, 2014 pISSN 1976-2283 eISSN 2005-1212 http://dx.doi.org/10.5009/gnl14005

@ This is an Open Access article distributed under the terms of the Creative Commons Attribution Non-Commercial License (http://creativecommons.org/licenses/by-nc/4.0) which permits unrestricted non-commercial use, distribution, and reproduction in any medium, provided the original work is properly cited. 
meal on upper gastrointestinal symptoms and gastric myoelectrical activity in healthy volunteers. It was hypothesized that a high-fat liquid meal would induce dyspepsia symptoms and gastric dysrhythmias, and that supplements of lipase would decrease postprandial symptoms and improve gastric myoelectrical activity.

\section{MATERIALS AND METHODS}

\section{Participants}

Twenty-eight volunteers were recruited with advertisements to participate in a double-blind, placebo-controlled, crossover trial. The medical history of each volunteer was thoroughly reviewed, physical examinations were performed, and water-load tests with electrogastrography (EGGs) were conducted to evaluate gastric myoelectrical responses to a physical challenge. ${ }^{17}$ In order for volunteers to be enrolled, each of these assessments was required to be normal. Twelve volunteers were excluded because they exhibited abnormal EGG responses during the water-load test (Fig. 1); they did not differ demographically from the 16 volunteers who met the inclusion criteria. The enrolled participants included 12 males and four females, aged 23 to 61 years (mean age, 31 years). Participants were fasted after midnight before each study session began the next morning. Two hours before the study, participants ingested $118 \mathrm{~mL}$ (4 oz) of apple juice and one piece of white toast and then continued to fast. Participants refrained from taking any medication, smoking cigarettes, or consuming alcohol 48 hours prior to their study visits. The use of human participants was approved by the Wake Forest University Health Sciences Institutional Review Board, and all participants provided written informed consent prior to the collection of any data.

\section{EGG}

EGGs were recorded using standard methods in order to assess gastric myoelectrical activity. ${ }^{4,18}$ For each time period of interest, estimates of the percentage of EGG power within the bradygastria frequency bandwidth (1.00 to 2.50 cycles/min [cpm]), the normal range (2.50 to $3.75 \mathrm{cpm}$ ), the tachygastria frequency bandwidth (3.75 to $10.00 \mathrm{cpm}$ ), and the duodenal-respiratory range (10.00 to $15.00 \mathrm{cpm}$ ) were obtained by dividing the power in those frequency ranges by estimates of total EGG power (1.00 to $15.00 \mathrm{cpm})^{4,18}$

\section{Procedure}

After a 15-minute baseline period, participants were given a high-fat meal (Pulmocare ${ }^{\circledR}$; Abbott Laboratories, Abbott Park, IL, USA) that was 55\% fat, 28\% carbohydrates, and 17\% protein (237 mL, $355 \mathrm{kcal}$ ). The meal was consumed in 5 minutes. A capsule containing $280 \mathrm{mg}$ of acid-resistant lipase (Amano Enzyme USA, Elgin, IL, USA) or placebo was administered immediately before ingestion of the meal. The order of conditions was counterbalanced, and visits were separated by at least 1 week (Fig. 1). At each visit, individuals completed a $100-\mathrm{mm}$ visual analog scale (VAS) indicating from 0 to 100 their intensity of stomach fullness, bloating, and nausea. The VAS was completed at baseline, immediately after the meal (Time 0), and at 10, 20, 30, 45, and 60 minutes after the meal. EGGs were recorded during the baseline period and throughout the 60 minutes following ingestion of the test meal.

\section{Data analysis}

The percentage of EGG activity in each frequency bandwidth was compared between conditions and over time with a $2 \times 6$ repeated measures analysis of variance (ANOVA) with condition as one within-subjects variable (placebo or lipase), and time as the other within-subjects variable (baseline, 10, 20, 30, 45, and 60 minutes). Similarly, ratings of stomach fullness, bloating, and nausea were compared between conditions and over time with a $2 \times 7$ repeated measures ANOVA with condition as one within-subjects variable (placebo or lipase), and time as the other within-subjects variable (baseline, immediately after the meal, 10, 20, 30, 45, and 60 minutes). The $\alpha$ level was set at 0.05 for all comparisons. Follow-up pairwise comparisons of the two conditions were conducted for specific points in time when warranted. Paired t-tests with the $\alpha$ level set at 0.05 were used

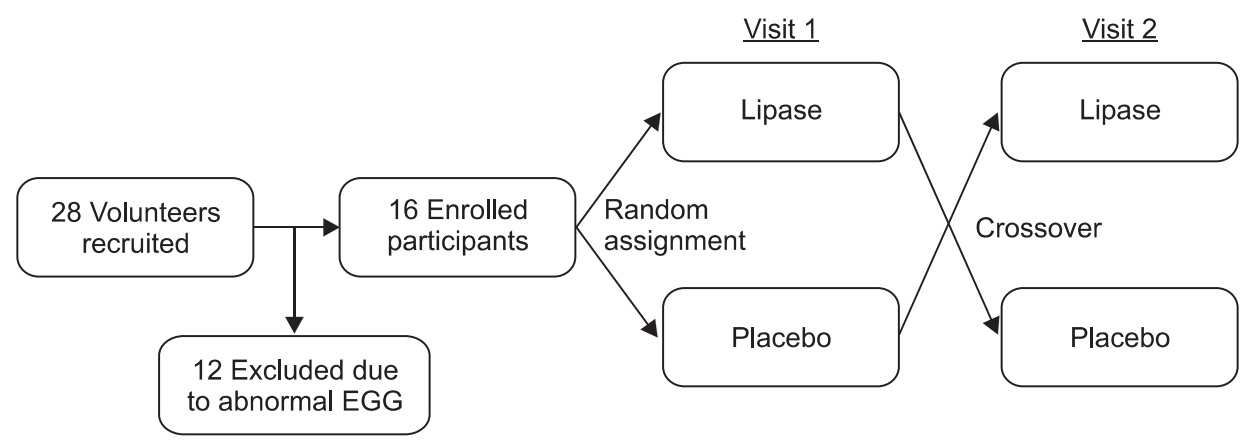

Fig. 1. Experimental design flowchart. Of the 28 volunteers who were recruited to participate, 16 met the inclusion criteria for enrollment; the other 12 exhibited abnormal electrogastrogram (EGG) responses to the water-load test. In this placebo-controlled crossover design, the enrolled participants were randomly assigned to receive either lipase or placebo during Visit 1, and the other treatment was administered during Visit 2. Visits were separated by at least 1 week. 
Table 1. Upper Gastrointestinal Symptoms as a Function of the Time Period and Experimental Condition

\begin{tabular}{|c|c|c|c|c|c|c|c|c|}
\hline \multirow{2}{*}{ Condition } & \multicolumn{7}{|c|}{ Time period, min } & \multirow{2}{*}{ Total } \\
\hline & Baseline & 0 & 10 & 20 & 30 & 45 & 60 & \\
\hline \multicolumn{9}{|c|}{ Stomach fullness } \\
\hline Lipase & $3.0 \pm 0.7$ & $18.2 \pm 3.3$ & $19.6 \pm 3.3$ & $14.0 \pm 2.4$ & $10.9 \pm 2.0$ & $11.2 \pm 2.2$ & $9.2 \pm 2.4$ & $13.9 \pm 2.0$ \\
\hline Placebo & $5.7 \pm 1.5$ & $26.7 \pm 5.9$ & $23.3 \pm 4.3$ & $20.4 \pm 4.3$ & $19.1 \pm 4.1$ & $17.9 \pm 4.4$ & $10.5 \pm 2.5$ & $19.7 \pm 3.9$ \\
\hline Overall & $4.3 \pm 0.8$ & $22.4 \pm 3.4$ & $21.5 \pm 2.7$ & $17.2 \pm 2.5$ & $15.0 \pm 2.4$ & $14.6 \pm 2.5$ & $9.8 \pm 1.7$ & $16.8 \pm 2.2$ \\
\hline \multicolumn{9}{|l|}{ Bloating } \\
\hline Lipase & $2.4 \pm 0.5$ & $4.5 \pm 1.7$ & $7.0 \pm 2.9$ & $5.5 \pm 1.6$ & $5.2 \pm 1.9$ & $5.9 \pm 2.8$ & $3.6 \pm 1.1$ & $5.3 \pm 1.7$ \\
\hline Placebo & $2.4 \pm 0.5$ & $6.0 \pm 3.3$ & $6.9 \pm 2.3$ & $6.4 \pm 2.4$ & $4.8 \pm 1.4$ & $3.3 \pm 0.9$ & $3.0 \pm 0.7$ & $5.1 \pm 1.6$ \\
\hline Overall & $2.4 \pm 0.3$ & $5.3 \pm 1.8$ & $7.0 \pm 1.8$ & $5.9 \pm 1.4$ & $5.0 \pm 1.2$ & $4.6 \pm 1.5$ & $3.3 \pm 0.6$ & $5.2 \pm 1.1$ \\
\hline \multicolumn{9}{|l|}{ Nausea } \\
\hline Lipase & $2.4 \pm 0.5$ & $1.7 \pm 0.5$ & $4.2 \pm 1.2$ & $3.6 \pm 0.8$ & $3.9 \pm 0.9$ & $3.6 \pm 1.0$ & $3.5 \pm 0.9$ & $3.4 \pm 0.8$ \\
\hline Placebo & $2.0 \pm 0.4$ & $2.1 \pm 0.4$ & $4.3 \pm 1.1$ & $3.6 \pm 0.7$ & $3.4 \pm 0.8$ & $3.4 \pm 0.9$ & $3.4 \pm 0.9$ & $3.4 \pm 0.7$ \\
\hline Overall & $2.2 \pm 0.3$ & $1.9 \pm 0.3$ & $4.2 \pm 0.8$ & $3.6 \pm 0.5$ & $3.7 \pm 0.6$ & $3.5 \pm 0.6$ & $3.5 \pm 0.6$ & $3.4 \pm 0.5$ \\
\hline
\end{tabular}

Time periods are expressed as minutes after the completion of the test meal. Time period " 0 " represents the symptom rating obtained immediately after the completion of the test meal. "Total" represents the mean symptom ratings across all time periods combined. "Overall" represents the mean symptom ratings at each time period of both conditions combined. Values represent the means \pm standard errors of the means and are based on visual analog scale scores ranging from 0 to 100 . Stomach fullness, bloating, and nausea were significantly higher at time 0 than at baseline (based on the "Overall" means) and were significantly lower at 45 minutes than at $0(\mathrm{p}<0.05)$. Stomach fullness was significantly lower in the lipase condition than in the placebo condition at 20 and 30 minutes $(\mathrm{p}<0.05)$.

for this purpose.

\section{RESULTS}

\section{Effects of test meal on symptoms and gastric myoelectri- cal activity}

Significant effects of ingestion of the fatty meal were observed for stomach fullness, $F(6,90)=15.31, \mathrm{p}<0.001$, bloating, $F(6,90)=3.10, \mathrm{p}<0.05$, and nausea, $F(6,90)=7.30, \mathrm{p}<0.001$. Reports of stomach fullness, bloating, and nausea were increased significantly 10 minutes after ingestion of the fatty meal (Table 1). By 45 minutes after the meal, stomach fullness, bloating, and nausea had all decreased significantly compared with the 10-minute period immediately after the meal (Fig. 2). Significant effects of ingestion of the fatty meal were also observed for normal EGG activity, $F(5,75)=2.76, \mathrm{p}=0.02$, and tachygastria, $F(5,75)=2.79, p=0.02$. Normal $3 \mathrm{cpm}$ gastric myoelectrical activity decreased significantly, and tachygastria increased significantly 10 minutes after the fatty meal (Table 2). By 45 minutes after the meal, tachygastria had decreased significantly compared with the 10-minute period immediately after the meal, and normal $3 \mathrm{cpm}$ gastric myoelectrical activity had increased significantly (Fig. 3).

\section{Effects of lipase supplementation on symptoms and gas- tric myoelectrical activity}

Acid-resistant lipase supplementation reduced stomach fullness after the fatty meal compared with placebo, $F(1,15)=4.35$,

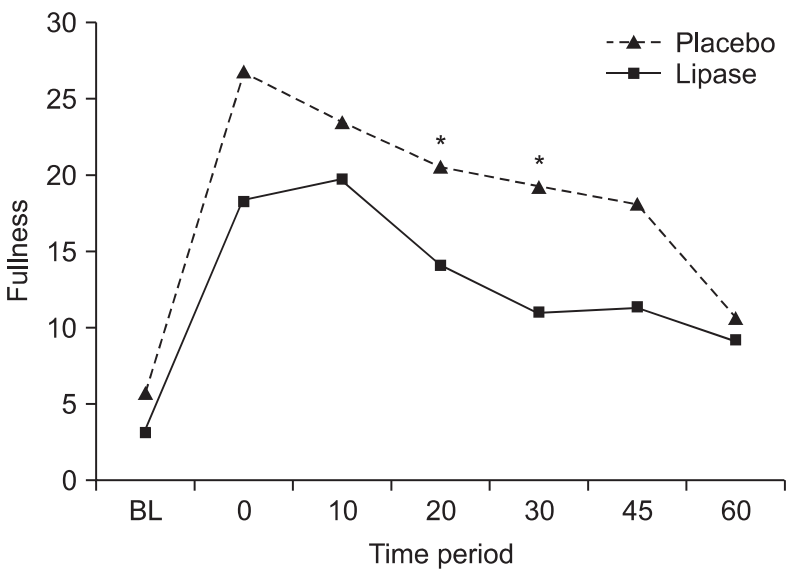

Fig. 2. Ratings of stomach fullness as a function of time period and experimental condition. Time periods are expressed as minutes after the completion of the high-fat test meal; "BL" represents the baseline period. Time period "0" represents the period immediately after the test meal was consumed. Stomach fullness increased significantly from baseline to 10 minutes and decreased significantly from 10 to 45 minutes $(p<0.05)$ after placebo or lipase treatment. Ratings of stomach fullness were significantly lower in the lipase condition than in the placebo condition at 20 and 30 minutes after the meal $(p<0.05)$. The asterisks indicate the time periods in which stomach fullness was significantly lower with lipase compared to placebo.

$\mathrm{p}<0.05$. This difference reached statistical significance at 20 and 30 minutes after the meal (Fig. 2). Postprandial symptoms of bloating and nausea were not affected by lipase supplementation. Lipase supplementation did not affect gastric myoelectrical 
Table 2. Estimates of Bradygastria, Normal Electrogastrogram Activity, and Tachygastria as a Function of Time Period and Experimental Condition

\begin{tabular}{|c|c|c|c|c|c|c|c|}
\hline \multirow{2}{*}{ Condition } & \multicolumn{6}{|c|}{ Time period, min } & \multirow{2}{*}{ Total, mir } \\
\hline & Baseline & 10 & 20 & 30 & 45 & 60 & \\
\hline \multicolumn{8}{|l|}{ Bradygastria } \\
\hline Lipase & $36.7 \pm 2.2$ & $33.8 \pm 2.9$ & $31.1 \pm 4.6$ & $39.7 \pm 3.3$ & $36.6 \pm 3.5$ & $35.1 \pm 3.2$ & $33.8 \pm 2.4$ \\
\hline Placebo & $38.8 \pm 3.3$ & $39.3 \pm 2.2$ & $40.5 \pm 3.9$ & $33.1 \pm 4.3$ & $31.5 \pm 2.3$ & $31.4 \pm 3.2$ & $35.8 \pm 2.3$ \\
\hline Overall & $37.8 \pm 2.0$ & $36.6 \pm 1.9$ & $35.8 \pm 3.1$ & $31.4 \pm 2.7$ & $34.1 \pm 2.2$ & $33.3 \pm 2.2$ & $34.8 \pm 1.7$ \\
\hline \multicolumn{8}{|c|}{ Normal EGG activity } \\
\hline Lipase & $27.1 \pm 2.6$ & $21.7 \pm 4.1$ & $23.2 \pm 3.7$ & $27.4 \pm 2.8$ & $23.9 \pm 2.7$ & $27.1 \pm 3.4$ & $25.1 \pm 2.2$ \\
\hline Placebo & $31.8 \pm 3.7$ & $21.5 \pm 2.5$ & $26.3 \pm 2.8$ & $30.1 \pm 5.0$ & $32.0 \pm 3.5$ & $34.9 \pm 5.0$ & $29.4 \pm 2.4$ \\
\hline Overall & $29.4 \pm 2.2$ & $21.6 \pm 2.4$ & $24.8 \pm 2.3$ & $28.7 \pm 2.8$ & $28.0 \pm 2.3$ & $31.0 \pm 3.0$ & $27.2 \pm 1.7$ \\
\hline \multicolumn{8}{|l|}{ Tachygastria } \\
\hline Lipase & $25.3 \pm 1.3$ & $32.6 \pm 1.3$ & $32.5 \pm 4.3$ & $29.4 \pm 2.3$ & $28.3 \pm 3.1$ & $25.9 \pm 3.0$ & $29.0 \pm 2.4$ \\
\hline Placebo & $23.0 \pm 1.9$ & $29.8 \pm 2.0$ & $25.9 \pm 2.9$ & $27.7 \pm 2.3$ & $26.7 \pm 2.9$ & $26.6 \pm 3.6$ & $26.6 \pm 1.9$ \\
\hline Overall & $24.1 \pm 1.2$ & $31.2 \pm 1.9$ & $29.2 \pm 2.6$ & $28.5 \pm 2.0$ & $27.5 \pm 2.1$ & $26.3 \pm 2.9$ & $27.8 \pm 1.5$ \\
\hline
\end{tabular}

Time periods are expressed as minutes after the completion of the test meal. "Total" represents the mean electrogastrogram (EGG) estimates over all time periods combined. "Overall" represents the mean EGG estimates at each time period for both conditions combined. Values represent the means \pm standard errors of the means and are presented as percentages of total EGG power during each time period. Normal EGG activity was significantly lower at 10 minutes than at Baseline (based on "Overall” means) and was significantly higher at 45 minutes than at 10 minutes (p<0.05). Tachygastria was significantly higher at 10 minutes than at Baseline and significantly lower at 45 minutes than at 10 minutes (p<0.05). EGG activity in the duodenal-respiratory frequency range (10 to 15 cycles/min) was not significantly different across time periods and is not shown. No significant differences between the lipase and placebo conditions were observed during any time period for any frequency range.

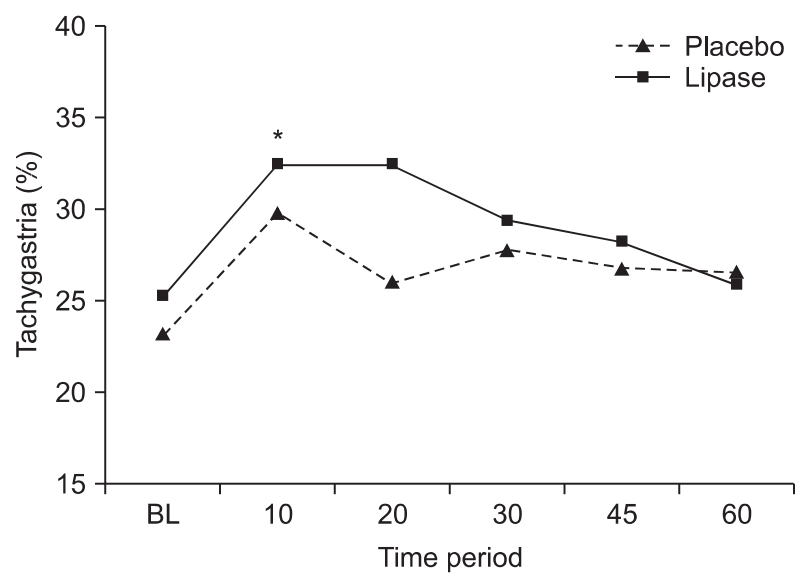

Fig. 3. Percentage of power in the tachygastria range as a function of time period and experimental condition. Time periods are expressed as minutes after the completion of the test meal; "BL" represents the baseline period. After the ingestion of the fatty meal, tachygastria was significantly higher at 10 minutes compared with baseline $(\mathrm{p}<0.05)$. The percentage distribution of tachygastria was not different between the experimental conditions. The asterisk indicates the time period in which tachygastria was significantly higher than at baseline.

activity at any postprandial time point compared with placebo (Fig. 3).

\section{DISCUSSION}

The results of this study demonstrated that a fatty liquid meal comprised of 55\% fat evoked symptoms of fullness, bloating, and nausea in healthy individuals, and that lipase supplementation significantly reduced perceptions of fullness after the meal. However, the ability of lipase supplementation to reduce fullness cannot be attributed to its effects on gastric myoelectrical activity; it could not be demonstrated that lipase can prevent the tendency of the high-fat meal to increase gastric dysrythmia and decrease normal gastric activity.

The significant increases in fullness, bloating, and nausea in healthy participants after the test meal are typical postprandial symptoms experienced after normal meals by patients with "dyspepsia” or PDS. ${ }^{3}$ The mechanism by which acid-resistant lipase supplements reduced stomach fullness in these healthy volunteers remains unclear, but further research is warranted given the impact of prolonged or uncomfortable fullness after meals experienced by many individuals with varying dyspepsia syndromes.

Prolonged fullness after meals is a common symptom in patients with functional dyspepsia, and gastroparesis is found in $30 \%$ to $40 \%$ of these dyspepsia patients. ${ }^{4}$ Prolonged postprandial fullness is a key symptom of gastroparesis and is attributed simply to slow emptying of the meal. Many healthy individuals, however, also experience prolonged fullness after meals, particularly fatty meals. Treatment options for postprandial dyspepsia symptoms such as uncomfortable fullness, early satiety, and abdominal discomfort or nausea remain poor. Lipase supplementation with meals may provide relief of symptomatic 
postprandial fullness.

While no physiological mechanism to explain the decreased fullness after lipase supplements can be definitively proposed on the basis of these data, we speculate that the effect of lipase on the breakdown of TG during the gastric phase of fat digestion resulted in the decreased sense of stomach fullness. Since the emptying of long chain fatty acids into the duodenum delays gastric emptying compared with the emptying of short chain fatty acids, ${ }^{14}$ we hypothesize that the lipase supplementation enhanced the normal actions of gastric lipases in hydrolyzing the TG in the test meal into fatty acids and mono- and diglycerides. Thus, the test meal may have been more rapidly emptied from the stomach in the presence of the increased lipase, and the sensation of fullness was then reduced over the postprandial time periods compared with placebo. Gastric emptying time data from these participants or duodenal fatty acid assays will be needed to confirm this hypothesis.

The pathophysiological mechanisms underlying functional dyspepsia and PDS remain poorly understood. ${ }^{3}$ The pathogenesis of dyspepsia symptoms ranges from gastroparesis ${ }^{3,4}$ to disorders of fundic accommodation or fundic contractions, ${ }^{19}$ to gastric dysrhythmias. ${ }^{17,20}$ Gastric dysrhythmias also occur in other conditions of nausea such as motion sickness, ${ }^{21}$ and the nausea and vomiting of pregnancy. ${ }^{22}$ In the present study, nausea and tachygastria increased in healthy participants after ingestion of the fatty meal, indicating gastric dysrhythmias can occur in healthy subjects after high-fat meals. Whether or not this high-fat meal induces nausea and gastric dysrhythmias on patients with PDS is unknown.

In our healthy subjects, enzyme supplementation did not affect nausea severity, although fullness was reduced. Thus, nausea, although induced by the fatty meal, was not eliminated by the presence of lipase, which indicates other mechanisms of nausea were elicited by the fatty meal. The effect of lipase supplements on fullness or nausea in patients with PDS has not been evaluated. It is interesting that protein drinks with ginger supplements do reduce nausea in patients with delayed nausea associated with previous cancer chemotherapy, ${ }^{23}$ but the mechanisms evoking the nausea are different since the fatty meal induces nausea within minutes of ingestion. In summary, the fatty meal induced immediate fullness, bloating and nausea, symptoms suggestive of PDS. Lipase administered with the meal but not placebo reduced the meal-induced fullness. Further exploration of acid-resistant lipase supplements in both healthy individuals and patients with PDS deserves attention.

\section{CONFLICTS OF INTEREST}

No potential conflict of interest relevant to this article was reported.

\section{ACKNOWLEDGEMENTS}

This study was sponsored in part by Amano Enzyme USA Co., Ltd. (Elgin, IL, USA).

\section{REFERENCES}

1. Talley NJ, Stanghellini V, Heading RC, Koch KL, Malagelada JR, Tytgat GN. Functional gastroduodenal disorders. Gut 1999;45 Suppl 2:II37-II42.

2. Talley NJ, Zinsmeister AR, Schleck CD, Melton LJ 3rd. Dyspepsia and dyspepsia subgroups: a population-based study. Gastroenterology 1992;102(4 Pt 1):1259-1268.

3. Drossman DA. Rome III: the functional gastrointestinal disorders. McLean: Degnon Associates, 2006.

4. Koch KL, Stern RM. Functional disorders of the stomach. Semin Gastrointest Dis 1996;7:185-195.

5. Suarez F, Levitt MD, Adshead J, Barkin JS. Pancreatic supplements reduce symptomatic response of healthy subjects to a high fat meal. Dig Dis Sci 1999;44:1317-1321.

6. Carey MC, Small DM, Bliss CM. Lipid digestion and absorption. Annu Rev Physiol 1983;45:651-677.

7. Aoubala M, Douchet I, Laugier R, Hirn M, Verger R, De Caro A. Purification of human gastric lipase by immunoaffinity and quantification of this enzyme in the duodenal contents using a new ELISA procedure. Biochim Biophys Acta 1993;1169:183-188.

8. Moreau H, Laugier R, Gargouri Y, Ferrato F, Verger R. Human preduodenal lipase is entirely of gastric fundic origin. Gastroenterology 1988;95:1221-1226.

9. Kleeberg J. The discovery of gastric lipase by Franz Volhard (1901). Z Gastroenterol 1971;9:646-647.

10. Renou C, Carrière F, Ville E, Grandval P, Joubert-Collin M, Laugier R. Effects of lansoprazole on human gastric lipase secretion and intragastric lipolysis in healthy human volunteers. Digestion 2001;63:207-213.

11. Armand M, Borel P, Pasquier B, et al. Physicochemical characteristics of emulsions during fat digestion in human stomach and duodenum. Am J Physiol 1996;271(1 Pt 1):G172-G183.

12. Carriere F, Barrowman JA, Verger R, Laugier R. Secretion and contribution to lipolysis of gastric and pancreatic lipases during a test meal in humans. Gastroenterology 1993;105:876-888.

13. Gargouri Y, Pieroni G, Riviere C, et al. Kinetic assay of human gastric lipase on short- and long-chain triacylglycerol emulsions. Gastroenterology 1986;91:919-925.

14. Schwizer W, Asal K, Kreiss C, et al. Role of lipase in the regulation of upper gastrointestinal function in humans. Am J Physiol 1997;273(3 Pt 1):G612-G620.

15. Carrière F, Renou C, Lopez V, et al. The specific activities of human digestive lipases measured from the in vivo and in vitro lipolysis of test meals. Gastroenterology 2000;119:949-960.

16. Borovicka J, Schwizer W, Mettraux C, et al. Regulation of gastric and pancreatic lipase secretion by CCK and cholinergic mecha- 
nisms in humans. Am J Physiol 1997;273(2 Pt 1):G374-G380.

17. Koch KL, Hong SP, Xu L. Reproducibility of gastric myoelectrical activity and the water load test in patients with dysmotility-like dyspepsia symptoms and in control subjects. J Clin Gastroenterol 2000;31:125-129.

18. Koch KL, Stern RM. Handbook of electrogastrography. New York: Oxford University Press, 2003.

19. Tack J, Piessevaux H, Coulie B, Caenepeel P, Janssens J. Role of impaired gastric accommodation to a meal in functional dyspepsia. Gastroenterology 1998;115:1346-1352.

20. Parkman HP, Miller MA, Trate D, et al. Electrogastrography and gastric emptying scintigraphy are complementary for assessment of dyspepsia. J Clin Gastroenterol 1997;24:214-219.

21. Stern RM, Koch KL, Stewart WR, Lindblad IM. Spectral analysis of tachygastria recorded during motion sickness. Gastroenterology 1987;92:92-97.

22. Koch KL, Stern RM, Vasey M, Botti JJ, Creasy GW, Dwyer A. Gastric dysrhythmias and nausea of pregnancy. Dig Dis Sci 1990;35:961-968.

23. Levine ME, Gillis MG, Koch SY, Voss AC, Stern RM, Koch KL. Protein and ginger for the treatment of chemotherapy-induced delayed nausea. J Altern Complement Med 2008;14:545-551. 